\title{
Are We Causing Antibiotic Resistance with Antibiotic Abuse? A Study among Dentists
}

\section{BHUVAN DEEP GUPTA*1 iD, INSHA NISSAR ${ }^{2}$, AKANKSHA MONGA $^{3}$}

INTRODUCTION: With the invention of any new technology their comes the boon and curse both. The invention and use of antibiotics comes a problem of antibiotic resistance which is much more in extent than treating the infectious disease. Keeping this in mind the WHO in 2011 gave the theme "combat drug resistance- No action today, No cure tomorrow" which was very significant. The present study was done with the aim to know the prescription pattern of antibiotics for various dental procedures by dental practitioners.

B MATERIALS AND METHODS: A specially prepared questionnaire exclusively designed for the study recording all the required relevant general information and information related to antibiotic prescribing patterns was used for data collection. The questionnaire consisted of three sections. The first part of the questionnaire collected the demographic details of the study population like age, gender, Graduate or postgraduate degree, area of specialization and years of practice. In the second section the Questions related to antibiotics use in certain dental clinical procedures and conditions in apparently healthy people were asked from the participants. In the last section of the questionnaire the participants were asked about the questions related to antibiotics use for certain dental clinical procedures in medically compromised cases.

RESULTS: Questionnaire response rate of $73 \%$ was recorded. The study showed Augmentin to be the first choice of antibiotic by most of the respondents. The study showed that $64 \%$ of the endodontists and $74 \%$ of the general dentists prescribed antibiotics during root canal therapy where ideally operative intervention would have sufficed. Overuse of antibiotics for routine scaling and extraction was observed.

CONCLUSION: The dental profession as a whole needs to acquire a deeper understanding of the global effects of unnecessary antibiotic prescription. Antibiotics when judiciously used are precise life-saving drugs.

KEYWORDS: Amoxicillin, Antibiotics, Drug Resistance

\section{INTRODUCTION}

With the invention of any new technology their comes the boon and curse both. When Dr Alexander Fleming invented antibiotics he was not aware that what he is doing for the benefit of mankind will become curse one day for human race by its injudicious use. In the recent past there have been dramatic increase in the use of antibiotics by both medical and dental professionals for treatment of even the minor infections and this indiscriminate use of antibiotic has caused antibiotics resistance which has become a worldwide problem now and it is increasing at the alarming rate. ${ }^{1}$

There is not much evidence about how dentist's indiscriminate use of antibiotics contributes to this menance. $^{2}$ In dentistry most often antibiotic prescription is mainly for prophylactic use for certain systemic diseases which may be life- threatening and also for the prevention of postoperative infections. There are various school of thoughts who advocate the prophylactic use of antibiotics in healthy people and patients, which is an important criterion medicolegally for medically compromised patients. ${ }^{3}$ we have to weigh the benefits of giving prophylactic antibiotic in comparison to their risks of allergic reactions, side effects, and escalating problems of antimicrobial resistance. ${ }^{4,5}$
There have been many guidelines published from time to time for the judicious use of antibiotics but recommendations often clash. ${ }^{6}$ From this perspective, it is not surprising that evidence of overuse has been found in other studies on antibiotic prophylaxis administered by general dental practitioners. ${ }^{6,7}$ The theme of "World Health Day 2011" was to combat drug resistance-"No action today, No cure tomorrow". This is very applicable at this stage, as the present study categorically demonstrates the issues related to the vast concerns regarding unsystematic use of antibiotics, leading to a bleak tomorrow where cures may be few.

It was found after doing the extensive literature search that there were very few studies done in India related to the antibiotic prescription pattern and role of dentists to the development of antimicrobial resistance in India. Thus, we designed this study to determine the antibiotic prescribing practices among the dentist population in a large suburban city of India.

\section{MATERIALS AND METHOD}

This study was a cross-sectional study to determine the antibiotic prescribing practices among dentists in Noida \& Greater Noida. All the dentists working in Noida \& Greater Noida were invited to participate and 
those who gave their consent to participate formed the sample population for the study. Voluntary, written informed consent was obtained from dentists who participated in this study telling them about the purpose of the study and also informing that their identity will be kept confidential. Ethical clearance was taken from the Institutional ethical committee prior to the start of the study.

A specially prepared questionnaire exclusively designed for the study recording all the required relevant general information and information related to antibiotic prescribing patterns was used for data collection. The identity of the participating dentist was kept confidential. The pilot study was done on a small group of dentists to check the viability and applicability of the questionnaire. The necessary changes were done in the questionnaire after the pilot study.

The sampling methodology used in the study was the convenience sampling. A self- administered, pretested questionnaire was used. The questionnaire consisted of three sections. The first part of the questionnaire collected the demographic details of the study population like age, gender, Graduate or postgraduate degree, area of specialization and years of practice. In the second section the Questions related to antibiotics use in certain dental clinical procedures and conditions in apparently healthy people were asked from the participants. In the last section of the questionnaire the participants were asked about the questions related to antibiotics use for certain dental clinical procedures in medically compromised cases. The questionnaire was sent to all the dentists in the Noida and Greater Noida by hand or by email. The completely filled forms were collected and were numerically coded and entered into Microsoft Excel and Statistical Package for Social Science was used for analysis.

\section{RESULTS}

Out of total 155 forms send to the dentists of Noida and Greater Noida we received back 113 filled forms with a response rate of $73 \%$. The total 113 received forms were scrutinised and it was found that only 100 forms were completely filled, so the final sample size for the study population was 10o.there were total of 100 dentists who participated in the study. Out of total 100 dentists there were 63 general Dental Practitioners, 16 Endodontists, o9 Oral Surgeons, 05 Periodontists, 03 Orthodontists and 04 Pedodontists.
There were 72 males and 28 females in the study population. The mean age of practice was found to be 5.2 years among the study subjects.

Table 1 depicts the antibiotic prescription practice among the study population for different dental conditions. It clearly showed that augmentin (combination of Amoxicillin + Clavulanic) acid was the most preferred drug followed by cefixime, amoxicillin \& amoxicillin + cloxacillin, whereas in periodontal conditions doxycycline was the most preferred drug of choice by the dentists.

In our stud we compare the antibiotic prescription patter among specialist and general dentists for various dental conditions. During the comparison between Endodontists \& General Dentists antibiotic preferences dentists during root canal treatment it was seen that $64 \%$ of Endodontists favored performing root canal treatment under antibiotic coverage, whereas among general dentists $74 \%$ preferred antibiotic coverage during root canal treatment. The difference in choosing the antibiotic varied between two groups and it was statistically significant $(\mathrm{p}<0.05)$ [ Table 2].

During the comparison between Oral surgeon \& general dentists it was observed that only $36 \%$ of the oral surgeons preferred giving prophylactic antibiotics before extraction of third molar in normal healthy individuals whereas majority of the general dentists $78 \%$ gave prophylactic antibiotics to their patients before extraction of third molar[Table 3].

In case of medically compromised cases undergoing dental treatment, [Table 4] Majority of the dentists preferred to prescribe antibiotics for medically compromised cases during scaling, tooth removal, and during root canal treatment. It was found that in cases of medically compromised patients amoxicillin was the first drug of choice.

When we asked the study population the question: Do you prefer to seek advice from the physician to provide prophylactic antibiotics in case of medically compromised cases, majority of the dentists (75\%) said "yes" and only $25 \%$ of the dentists answered "no."

In response to the question "If the patient is already on antibiotics prescribed by a general physician for some other medical condition, what do you do?" It was found 


\begin{tabular}{|c|c|c|c|c|c|c|c|c|c|c|c|}
\hline $\begin{array}{c}\text { ORAL } \\
\text { CONDITIONS }\end{array}$ & $\begin{array}{r}\text { WHI } \\
\text { L } \\
\text { ANT }\end{array}$ & $\begin{array}{l}\text { HER } \\
\text { E } \\
\text { IOTI }\end{array}$ & AMOXICILLIN & $\begin{array}{c}\text { AMOXICILLIN } \\
\& \\
\text { CLOXACILLIN }\end{array}$ & DOXYCYCLINE & $\begin{array}{c}\text { OFLOXACIN } \\
\& \\
\text { ORNIDAZO } \\
\text { LE }\end{array}$ & CEFIXIME & AUGMENTIN & CIPLOX TZ & GENTAMICIN & METRONIDAZOLE \\
\hline & YES & NO & & & & & & & & & \\
\hline $\begin{array}{c}\text { IRREVERSIBL } \\
\text { E PULPITIS }\end{array}$ & 82 & 18 & 22 & 4 & & 24 & 15 & 32 & 3 & & \\
\hline $\begin{array}{c}\text { SPACE } \\
\text { INFECTION }\end{array}$ & 90 & 10 & 10 & & & & 36 & 38 & & 10 & 6 \\
\hline $\begin{array}{c}\text { PERIAPICAL } \\
\text { ABSCESS } \\
\end{array}$ & 88 & 12 & & 50 & & 7 & 15 & 4 & 16 & & 8 \\
\hline $\begin{array}{c}\text { EXTRACTION } \\
\text { OF TOOTH }\end{array}$ & 84 & 16 & 48 & & & 12 & 6 & 24 & 10 & & \\
\hline $\begin{array}{l}\text { PERIODONT } \\
\text { AL SURGERY }\end{array}$ & 70 & 25 & & & 46 & 10 & 22 & 18 & & & 4 \\
\hline $\begin{array}{c}\text { DISIMPACTI } \\
\text { ON } \\
\end{array}$ & 87 & 13 & 15 & 2 & & 3 & 34 & 26 & 10 & 5 & 5 \\
\hline $\begin{array}{c}\text { PERICORONI } \\
\text { TIS }\end{array}$ & 77 & 23 & 26 & 15 & 5 & 5 & 14 & 24 & 11 & & \\
\hline
\end{tabular}

Table 1. Distribution and Comparison of Antibiotic Prescription Pattern among Dentists in Various Conditions

\begin{tabular}{|c|c|c|c|c|c|}
\hline & DO YOU PRESCRIBE ANTIBIOTIC & AMOXICILLIN (\%) & AUGMENTIN (\%) & CEFIXIME (\%) & OFLOXACIN \& ORNIDAZOLE (\%) \\
\hline Endodontists & Yes (\%) & No (\%) & & & 13 \\
\hline General Dentists & 64 & 36 & 35 & 46 & 52 \\
\hline & 74 & 26 & 42 & Chi square test $=29.8512, \mathrm{p}=0.0002$ & 12 \\
\hline
\end{tabular}

Table 2. Distribution and Comparison of Antibiotic Preference among Endodontists and General Dentists During Root Canal Treatment 


\begin{tabular}{|c|c|c|c|c|c|c|}
\hline & \multicolumn{2}{|c|}{$\begin{array}{l}\text { PRESCRIBE } \\
\text { ANTIBIOTIC }\end{array}$} & $\begin{array}{c}\text { AMOXICILLIN } \\
(\%)\end{array}$ & $\begin{array}{c}\text { AUGMENTIN } \\
(\%)\end{array}$ & $\begin{array}{l}\text { CEFIXIME } \\
(\%)\end{array}$ & $\begin{array}{c}\text { OFLOXACIN \& } \\
\text { ORNIDAZOLE (\%) }\end{array}$ \\
\hline & Yes $(\%)$ & No $(\%)$ & & & & \\
\hline $\begin{array}{c}\text { ORAL } \\
\text { SURGEONS }\end{array}$ & 36 & 64 & 70 & 10 & & 20 \\
\hline \multirow[t]{2}{*}{$\begin{array}{l}\text { GENERAL } \\
\text { DENTISTS } \\
\end{array}$} & 78 & 22 & 65 & 25 & & 10 \\
\hline & \multicolumn{2}{|c|}{$\begin{array}{l}\text { Chi square test } \\
=0.142, p=0.59\end{array}$} & & \multicolumn{3}{|c|}{ Chi square test $=30.7521, p=0.0002$} \\
\hline
\end{tabular}

Table 3. Distribution and Comparison of Antibiotic Preference among Oral Surgeons and General Dentists before Third Molar Removal

\begin{tabular}{|c|c|c|c|c|c|c|c|}
\hline \multirow{2}{*}{ SYSTEMIC DISEASE } & \multicolumn{3}{c|}{ ORAL PROPHYAXIS } & \multicolumn{2}{c|}{ EXTRACTION } & \multicolumn{2}{c|}{ ROOT CANAL TREATMENT } \\
\cline { 2 - 7 } & Yes (\%) & No (\%) & Yes (\%) & No (\%) & Yes (\%) & No (\%) \\
\hline DIABETES & 35 & 65 & 68 & 32 & 56 & 44 \\
\hline HYPERTENSION & 28 & 72 & 48 & 52 & 51 & 49 \\
\hline MYOCARDIAL INFARCTION & 54 & 46 & 72 & 28 & 76 & 24 \\
\hline BY PASS SURGERY & 64 & 36 & 85 & 15 & 88 & 12 \\
\hline KIDNEY TRANSPLANTATION & 45 & 55 & 50 & 50 & 75 & 25 \\
\hline
\end{tabular}

Table 4. The Preference of Antibiotic In Medically Compromised Patients for Routine Dental Procedures

that only $26 \%$ of the dentists preferred to consult physician and then to prescribe, whereas $74 \%$ of the dentists preferred to continue the same drug regimen.

When the study population was asked Do you prefer antibiotic sensitivity testing before prescribing antibiotics in case of severe facial space infections? Majority of the dentists (64\%) said "no" and the rest $36 \%$ of the dentists answered "yes."

\section{DISCUSSION}

The results of this survey indicate that there is a wide range of antibiotics prescribed by dentists in Noida \& Greater Noida. This study was the one of its kind to evaluate a large dental population in a major North Indian city. This study was conducted in Noida \& Greater Noida, which is an upcoming educational hub with a majority of the patient population from rural background where sale of over the counter drug is also more common.

The study showed Augmentin to be the first choice of antibiotic by most of the respondents. There was a wide range in the preference for prescribing antibiotics with wide difference in the dosage and duration for a similar condition. It was seen that in cases of pericoronitis, $77 \%$ of the dentists preferred to use antibiotics. In these situations judicious use of NSAIDs \& warm saline rinses to decrease the symptoms of pain and inflammation initially can prevent the inadvertent use of antibiotics.
While doing surgical impactions in normal healthy individuals, $36 \%$ of the oral surgeons and $78 \%$ of the general dental practitioners prescribed antibiotics to prevent postsurgical infections. Whereas it has been proved in many studies that Postoperative infections from surgical extractions are very low and there are enough evidences which shows that antibiotics have very less effect in treating post extraction infections. ${ }^{8,9}$ Antibiotics should never be used as a substitute for good surgical and aseptic operating techniques. ${ }^{10}$

Endodontic treatment in healthy individuals precludes the use of antibiotics, when good technique is employed in canal preparation, disinfection and obturation." "Here it was found that $64 \%$ of the endodontists and $74 \%$ of the general dentists desired to prescribe antibiotics during root canal therapy where operative intervention alone would have sufficed. ${ }^{8}$

Unfortunately, dentists still prescribe antibiotics in these conditions. ${ }^{12-19}$

It was seen that for treatment of periodontal conditions, periodontists preferred doxycycline more commonly when compared with other dentists who preferred cefixime and Augmentin. It is very much evident that periodontal conditions respond better with doxycycline due to its broad-spectrum action, higher concentration 
in gingival crevicular fluid, ${ }^{20,21}$ and also it has superior effectiveness against anaerobes. Lack of awareness regarding the efficacy of doxycycline could be a major contributing factor for overuse of Cefixime \& Augmentin in these situations.

This study also explored the use of prophylactic antibiotics in medically compromised cases such as Diabetes, Hypertension, myocardial infarction, kidney transplant, heart valve prosthesis, and hip prosthesis. A large proportion of the respondents prescribed prophylactic antibiotics for tooth removal and root canal treatment procedures among these cases. Augmentin was the most prescribed antimicrobial for these procedures, in concordance with other studies. ${ }^{7}$ Dentists seem to disregard the ideal recommendation to perform sensitivity tests.

\section{CONCLUSION}

- Augmentin (Amoxicillin + Clavulanic acid) was the first choice of drug among most of the study participants; both as a therapeutic drug and a prophylactic drug of choice.

- It was concluded that there was overuse of the antibiotics during certain routine surgical procedures, endodontic therapy which can be avoided if it is done with utmost care and aseptic conditions.

- The practice of doing antibiotic sensitivity tests in medically compromised patients before prescribing the antibiotics and following prescribed guidelines for use of antibiotics needs to be emphasized.

\section{RECOMMENDATIONS}

- The dentists should be made more aware about the proper guidelines for using antibiotics in the common dental conditions through workshops and CDE programs to prevent the menance of drug resistance.

- The dearth of studies regarding the prevailing situation in India suggest a necessity to do further systematic and extensive research to gain a better understanding of antibiotics, their use, and disuse.

- There should be more emphasis on the evidence based practice guidelines for prescribing antibiotics to the patients.

- The sale of over the counter drug also should be discouraged among the Indian population to decrease the antibiotic resistance.

\section{REFERENCES}

1. Preus HR, Albandar JM, Gjermo P. Antibiotic prescribing practices among Norwegian dentists. Scand J Dent Res. 1992;100:232-5.
2. Haas DA, Epstein JB, Eggert FM. Antimicrobial resistance: dentistry's role. J Can Dent Assoc. 1998;64:496-502.

3. Martin MV, Butterworth ML, Longman LP. Infective endocarditis and the dental practitioner: a review of 53 cases involving litigation. Br Dent J. 1997;182 (12):465-8. 4. Monitoring and management of bacterial resistance to antimicrobial agents: a World Health Organization symposium. Geneva, Switzerland, 29 November-2 December, 1995. Clin Infect Dis 1997;24 Suppl 1: S1-176. 5. Standing Committee of Science and Technology. Resistance to Antibiotics and Other Antimicrobial Agents. London: The stationary Office: House of 19 Lords; 1998.

6. Jaunay T, Sambrook P, Goss A. Antibiotic prescribing practices by South Australian general dental practitioners. Aust Dent J 200o;45:179-86; quiz 214.

7. Palmer NA, Pealing R, Ireland RS, Martin MV. A study of prophylactic antibiotic prescribing in National Health Service general dental practice in England. Br Dent J. 2000;189:43-6.

8. Longman LP, Preston AJ, Martin MV, Wilson NH. Endodontics in the adult patient: the role of antibiotics. J Dent 2000;28:539-48.

9. Rud J. Removal of impacted lower third molars with acute pericoronitis and necrotising gingivitis. $\mathrm{Br} \mathrm{J}$ Oral Surg. 1970;7:153-60.

10. Longman LP, Martin MV. The use of antibiotics in the prevention of post- operative infection: A reappraisal. Br Dent J. 1991;170:257-62.

11. Whitten BH, Gardiner DL, Jeansonne BG, Lemon RR. Current trends in endodontic treatment: report of a national survey. J Am Dent Assoc 1996;127:1333-41.

12. Palmer NO, Martin MV, Pealing R, Ireland RS. An analysis of antibiotic prescriptions from general dental practitioners in England. J Antimicrob Chemother 2000;46:1033-5.

13. Demirbas F, Gjermo PE, Preus HR. Antibiotic prescribing practices among Norwegian dentists. Acta Odontol Scand 2006;64:355-9.

14. Salako NO, Rotimi VO, Adib SM, Al-Mutawa S. Pattern of antibiotic prescription in the management of oral diseases among dentists in Kuwait. J Dent 2004;32:503-9.

15. Al-Haroni M, Skaug N. Knowledge of prescribing antimicrobials amongYemeni general dentists. Acta Odontol Scand 2006;64:274-80.

16. Öcek Z, Sahin H, Baksi G, Apaydin S. Development of a rational antibiotic usage course for dentists. Eur J Dent Educ 2008;12:41-7.

17. Yingling NM, Byrne BE, Hartwell GR. Antibiotic use by members of the American Association of 
Endodontists in the year 2000: report of a national survey. J Endod 2002;28:396-404.

18. Rodriguez-Núnez A, Cisneros-Cabello R,VelascoOrtega E, Llamas-Carreras JM,Tórres-Lagares D, Segura-Egea JJ.Antibiotic use by members of the Spanish Endodontic Society. J Endod. 2009;35:1198-203. 19. Mainjot A, D'Hoore W, Vanheusden A, Van Nieuwenhuysen JP. Antibiotic prescribing in dental practice in Belgium. Int Endod J 2009;42:1112-7.

20. Alger FA, Solt CW, Vuddhankanok S, Miles K. The histological evaluation of new attachement in periodontally diseased human roots treated with tetracycline-hydrochloride and fibronectin. J Periodontol 1990;61:447-55.

21. Bader HI, Goldhaber P. The passage of intravenously administered tetracycline in the gingival sulcus of dogs. J Oral Ther Pharmacol 1968;2:324-9.

Source of support: Nil, Conflict of interest: None declared

Cite this article as:

Gupta BD, Nisasr I, Monga A Are We Causing Antibiotic Resistance with Antibiotic

Abuse? A Study among Dentists. Int Healthc Res J. 2020;3(10):338-343. https://doi.org/10.26440/IHRJ/0310.01198

\section{AUTHOR AFFILIATIONS: $\left({ }^{*}\right.$ Corresponding Author $)$}

1. * Professor, Department of Public Health Dentistry, ITS Dental College, Greater Noida, UP, India

(ORCID ID: https://orcid.org/oooo-0oo3-3864-2474)

2. PG Student, Department of Public Health Dentistry, ITS Dental College, Greater Noida, UP, India

3. Senior Lecturer, Department of Public Health Dentistry, Manav Rachna Dental College, Faridabad, India 